\title{
Article choice by Persian EFL learners: Evidence against the Fluctuation Hypothesis?
}

\author{
Momenzade, Marjansadat $\bowtie$ \\ University of Isfahan, Iran (marymomen@yahoo.com) \\ Youhanaee, Manijeh \\ University of Isfahan, Iran (youhanaee_m@hotmail.com) \\ Kassaian, Zohreh \\ University of Isfahan,Iran (zkassaian@yahoo.com)
}

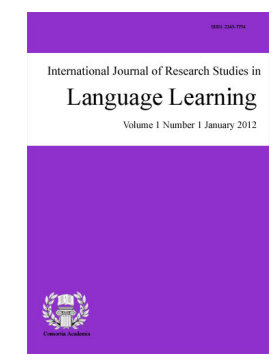

ISSN: 2243-7754 Online ISSN: 2243-7762

OPEN ACCESS

\section{Abstract}

The present study attempted to explore the acquisition of the English article system by Persian speakers. Using data elicited through a grammaticality judgment test and a translation test from forty-three learners at three levels of grammatical knowledge, it was shown that such learners had persistent difficulty in acquiring both definite and indefinite articles in English. Based on this study, it was only at the highly advanced level that learners showed mastery of the indefinite article but still remained non-native-like in their use of the definite article. Their performance also revealed sensitivity to NP function as the learners were more successful in supplying the article for object nouns. Despite the high proportion of article errors, data from Persian learners supported the predictions of the Fluctuation Hypothesis because the majority of errors were omitting the articles in obligatory contexts and not misusing the articles. Some directions are also provided for teaching the English article system to Persian speaking learners.

Keywords: article choice parameter; fluctuation hypothesis; definiteness; specificity; np function 


\section{Article choice by Persian EFL learners: Evidence against the Fluctuation Hypothesis?}

\section{Introduction}

The English article system has been a challenge from both teaching and learning perspectives for a long time. Ever since L2 English interlanguages have been studied, there has always been reported difficulty and dissatisfaction regarding the article system (McEldowney, 1977; Master, 1983; Ionin, Ko, \& Wexler, 2003; Ansarin, 2003, Ko, Ionin, \& Wexler, 2006; Atay, 2010 among others). Being such a noticeable area of difficulty, there have been numerous attempts to identify, analyze, and resolve the problem (Mobini, 2006; Dabaghi \& Tavakoli, 2009; Rahmani, 2010). A number of researchers have put theories forward to account for this common problem (Ionin, 2003) while others have focused on the pedagogical aspect and have suggested specific methods for teaching articles in English (Master, 1987).

Within the field of second language acquisition, Ionin's Article Choice Parameter and her Fluctuation Hypothesis (2003) specifically attend to the problem of learning the article system. Studies that have tested these two hypotheses using data from a variety of languages such as English, Korean, Polish, French, etc abound but those using data from Persian speakers, at least to our knowledge, are lacking. On the other hand, most studies testing the predictions of those theories have looked at L2 learners whose L1s lack articles (e.g. Korean). The question of article acquisition by those learners who speak a [+ article] mother tongue has been less attended to. Although there are a few studies documenting acquisition of English articles by speakers of [+article] languages like Spanish (Ionin, Zubizaretta, \& Maldonado, 2008), Greek (Hawkins et al., 2006), and Arabic (Jaensch \& Sarko, 2009), data from Persian learners of English can no doubt yield information that will help shed more light on the issue. The present study, then, aims, in part, at exploring Ionin's hypotheses as they apply to Persian L1 speakers who are learning English as a foreign language.

Considering the fact that definiteness as a feature exists in Persian but is only phonologically realized on indefinite nouns, this study also questions the degree of difficulty that such learners have with definite and indefinite articles in English. It is generally expected that such learners would have no difficulty with the indefinite article in English since there is an equivalent in Persian. The definite article, being unfamiliar in form and function, is expected to be problematic.

In what follows, a brief sketch of the two hypotheses proposed about the acquisition of the article system is presented and a short review of the studies having tested those hypotheses is included. This is followed by a description of how articles work in English and Persian. In section six, the specific questions and hypotheses forming the study are presented. The rest of the article attends to the specific details of the study including the methodology, results and discussion. The final part concludes the study with some implications for teaching English articles to Persian learners.

\subsection{Linguistic assumptions}

In recent discussions of the article system, two notions have been dominant: specificity and definiteness. Specificity, according to Ionin (2003), crucially differs from definiteness in that specificity concerns the speaker's intent to refer regardless of the hearer's knowledge status. It can be defined as "a semantic feature that makes reference to the knowledge state of the speaker concerning a uniquely salient discourse referent" (Ko, Perovic, Ionin, \& Wexler, 2008, p.119). Examples of specific and non-specific NPs are given below where a short account of English articles is presented.

Based on the English article system and data collected from other languages (Spanish, Chinese, Malay, Polish), Ionin (2003) proposes the Article Choice Parameter (ACP) which states that a language which has two articles distinguishes them as follows: 
Setting one: Articles are distinguished on the basis of specificity.

Setting two: Articles are distinguished on the basis of definiteness.

She also proposes the Fluctuation Hypothesis (FH) which states that L2 learners have full UG access to the two settings of the Article Choice Parameter and that L2 learners fluctuate between the two settings of the Article Choice Parameter until the input leads them to set this parameter to the appropriate value.

Considering learners who speak a [+article] first language then, ACP predicts that they would transfer the properties of L1 to the L2 situation. If articles in both L1 and L2 distinguish either definiteness or specificity, it is predicted that learners would be highly accurate in their article use even at low levels of language proficiency and there would be no fluctuation. If articles are used to mark definiteness in the first language whereas they are used to mark specificity in the second one, learners are expected to transfer the L1 property and use L2 articles to mark definiteness. Exposed to L2 input, then, learners come to realize that articles in the second language are used differently in which case the ACP predicts that learners have full access to the two settings and a period would, then, follow during which they fluctuate between using articles to mark definiteness or specificity. In other words, they would use articles sometimes to show definiteness and other times to show specificity. It is also predicted that, with enough exposure to the L2 input, such learners are ultimately able to use articles in a native-like fashion. For learners who speak a [-article] L1 and are learning a [+article] L2 no transfer is involved. They are expected to fluctuate between those two settings until the L2 input leads them to the right distinction.

In their study of a [+article] language, Ionin, Zubizarreta, and Maldonado (2008) show that Spanish learners of English are able to use articles accurately even from the beginning. This lack of fluctuation is explained by the fact that English and Spanish are alike regarding their article systems, both marking definiteness. Data from Russian and Korean adult learners of English which are both [-article] languages also confirm the predictions of the ACP (Ionin, Ko, \& Wexler, 2004). On the basis of such data, Ionin concludes that L2 learners have direct UG access to the two settings of the proposed parameter, and that a specificity distinction which cross-cuts a definiteness distinction actually exists. As for the question of how long the fluctuation lasts, Ionin, Ko, and Wexler argue that L2 learners from article-less languages continue to fluctuate even at advanced levels of English because they 'need to evaluate the discourse situation and decide whether the is marking the presupposition of uniqueness (from the hearer's perspective)' (2004, p. 51). Maybe it is possible for learners to evaluate the discourse situation and improve in accuracy in article use, but clearly some learners are more accurate than others who will continue not only to fluctuate but misuse articles in all contexts.

\section{Background Studies}

The Fluctuation Hypothesis (FH) has claims for the performance of learners who have a [- article] first language. As a result, most studies that have tested the predictions of the $\mathrm{FH}$ have investigated performance of learners from such article-less languages as Korean (Kim \& Lakshmanan, 2008; Ko, Ionin, \& Wexler, 2009), Japanese (Snape, Leung, \& Ting, 2006; Hawkins et al. 2006), Serbian (Avery \& Radišić, 2007; Ko, Perovic, Ionin, \& Wexler, 2008), Russian (Ionin, Zubizarreta, \& Maldonado, 2008; Ionin, Ko, \& Wexler 2008; Ionin, Zubizarreta, \& Philippov, 2009), and Chinese (Yang \& Ionin, 2009; Snape, 2009). When it comes to the languages with articles, however, two possibilities exist. Either such learners are able to transfer the way articles are used in their first language and the initial state in L2 acquisition for them is the L1 property, or they have access to universal grammar and fluctuate between the two settings of the ACP. In other words, although the FH does not make any predictions for languages that have an article system, two competing hypotheses can be made (Ionin, Zubizarreta, \& Maldonado, 2008):

Hypothesis one: Transfer overrides fluctuation.

Hypothesis two: Fluctuation overrides transfer. 
Based on the first hypothesis, L2 learners whose L1 has articles transfer article semantics from their L1 to their L2. L2 learners whose L1 lacks articles, then, exhibit fluctuation. But according to the second hypothesis, all L2 learners should fluctuate between definiteness and specificity in their L2 article choice. In their study of Spanish learners of English, Ionin et al. (2008) found support for the first of the above hypotheses. Being a language with articles that mark definiteness, Spanish is like English and so, Spanish speakers in their study were highly accurate in their article choice on both definites and indefinites, showing that L1 transfer has a role in L2 acquisition of article semantics. Other studies of Spanish learners' performance can be found in the literature with the same results. Spanish learners in both Mayo (2009) and Snape, Leung, and Ting (2006) provided support for the first of the above hypothesis as they performed in a native-like fashion in their article choice in English in both definites and indefinites and were equally unaffected by specificity.

Greek is a [+article] language in which articles encode definiteness like English. It can be expected, therefore, that Greek learners of English, too, are accurate in using articles in their L2. Hawkins et al. (2006) provided support for this claim since their Greek subjects predominantly chose the/a to mark definiteness/indefiniteness. Although the researchers didn't agree that the concepts of ACP and FH were in line with the minimalist approach, their data provided support for them anyway.

Another study that is based on data from a [+article] first language is that of Guella, Déprez, and Sleeman (2008). They investigated the possibility of L1 transfer in the article choice of Dutch learners of L2 Arabic. Dutch is a [+article] language in which articles are used to mark definiteness. Arabic, too, is an article-based language which has a definite article but no indefinite article. In more specific terms, their research tested such learners in order to investigate whether they transferred articles from Dutch, in their use of Arabic, or whether they fluctuated between a choice based either on definiteness or on specificity. The results of the study indicated that Dutch learners lexicalized Arabic articles according to specificity instead of definiteness. This study provided evidence for the second of the above hypotheses: that learners have access to UG and that fluctuation is inevitable.

There is even more evidence that fluctuation is a developmental property of interlanguage grammars. Zdorenko and Paradis (2008) tested the FH with a group of children with first languages with and without articles. They found that children from both L1 backgrounds did misuse the in specific indefinite contexts. Due to the nature of the task (storytelling), this was the only context to be examined. They concluded, then, that fluctuation overrode transfer.

The last study to be reviewed here is that of Jaensch and Sarko (2009) which is somehow different from other research cited so far. The difference lies in the language which was under investigation. While other studies focused on learners from languages which either had or did not have articles, this study took Arabic learners of English. Arabic has an overt definite article but lacks an overt indefinite article though indefiniteness as a feature is not lacking in Arabic and generally all bare nouns are interpreted as indefinite. The researchers predicted that such learners would transfer their L1 knowledge to the L2 and would, thus, be accurate in their use of the definite article in English but would also show fluctuation in their use of the indefinite article due to lack of such morphology in L1. There was evidence in data collected from the Arab participants that the researchers' predictions were correct and that such learners were correctly selecting articles based on definiteness and not specificity.

\subsection{The article system in English}

The English article system marks definiteness, not specificity. Therefore, definite DPs (determiner phrases) in English are marked by "the" and indefinite DPs by "a". As for specificity, DPs in English may come with "the" or "a" in both [ \pm specific] situations. Types of articles in English can be shown as follows: 


\section{Table 1}

Definiteness and Specificity in English

\begin{tabular}{ll}
\hline \multicolumn{1}{c}{ Category } & \multicolumn{1}{c}{ Examples } \\
\hline Indefinite, specific & 1. Sarah wants to talk to a colleague of mine, John Brown. \\
Indefinite, non-specific & $\begin{array}{l}\text { 2. Sarah wants to talk to a colleague of mine, but I don't know which one. } \\
\text { 3efinite, specific }\end{array}$ \\
$\begin{array}{l}\text { 3. Joan wants to present the prize to the winner but he doesn't want to receive it from } \\
\text { her. }\end{array}$ \\
$\begin{array}{l}\text { 4. Joan wants to present the prize to the winner so she'll have to wait around till the } \\
\text { race finishes. }\end{array}$
\end{tabular}

\subsection{The article system in Persian}

Anzali (1985) claims that there is no definite article in Persian, however, he believes that lack of an equivalent "the" in Persian does not mean that the notion of definiteness is not present; rather, it is only a morphological absence. Ghomeshi (2003), on the other hand, gives clear evidence that Persian does have a definite article but that this article is just realized in informal spoken language. An example she provides is:

$>$ Doxtar-e amad.

Girl-Def come. Past. 3SG

'The girl came.'

The stand taken in this study, then, is that definiteness as a feature exists in Persian (as it does in English) and that it is morphologically realized in the informal spoken language. Definite DPs in Persian can be specific or non-specific just like definite DPs in English:

○ Specific

bache gerye kard.

Child cry do-Past-3SG

'The child cried.'

○ Non-specific

emruz modir-e jaedid ra mo'arefi mikonand. miduni ki entexabshode?

Today manager-Ezafe new Obj introduce Pres-do-3Plu. Pres-know-2SG who chooses become-Pres?

'They are announcing the new manager today. Who do you think has been chosen?'

As for the indefinite article, linguists (Anzali, 1985; Ghomeshi, 2003) agree that Persian has two articles: the enclitic -i and the word "yek" which may appear individually or co-occur on indefinite nouns:

$>$ dar xiyaban mardi didam.

In street man-Indef see-Past-1SG

'I saw a man in the street.'

$>$ dar xiyaban yek maerd didam.

In street one man see-Past-1SG

'I saw a man in the street.'

$>$ daer xiyaban yek mardi didam.

In street one man-Indef see-Past-1SG

'I saw a man in the street.' 
Momenzade, M., Youhanaee, M., \& Kassaian, Z.

Indefinite nouns can also be specific or non-specific. Examples are:

○ Specific

mardi dar xiyaban be man hamle kard.

Man-Indef in street to me attack do-Past-3SG

'A man attacked me in the street.'

○ Non-specific

har ruz in park por az kudakani shad ast

Every day this park full of kids-Indef happy is

'This park is full of happy kids every day.'

One last point to mention regarding the indefinite article in Persian is that it can be frequently omitted, for example:

$>$ u mashin xarid.

He car buy-Past-3SG

'He bought a car.'

To sum up, English and Persian are similar in that both include definite and indefinite articles and that in both languages the articles are distinguished on the basis of definiteness and not specificity.

\section{Research questions and hypotheses}

With regard to the variation between English and Persian and the observations made in relation to the FH, the present study aims at answering the following questions:

$>$ Do Persian speakers at different levels of proficiency have varying degrees of difficulty with definite and indefinite articles in English?

$>$ Do Persian learners fluctuate in their use of the definite article in [+definite, -specific] contexts in English?

$>$ Do such learners transfer their knowledge of the indefinite article in L1 to the L2 situation?

Based on the recent research findings discussed above, the following hypotheses are made:

$>$ The definite article in English poses more difficulty for Persian learners than the indefinite article.

$>$ Persian learners are consistent in their use of the in definite contexts since they are able to transfer their knowledge of definiteness in $\mathrm{L} 1$ to the $\mathrm{L} 2$ context.

Persian learners are accurate in the use of the indefinite article and would use a in [-definite, +specific] contexts consistently because they are able to transfer the properties of their L1 to the L2 situation.

\section{Methodology}

\subsection{Participants}

The sample taking part in the present study consisted of forty-three Persian-speaking learners of English as a foreign language. Based on the Oxford Quick Placement Test (2001), eighteen elementary, fourteen intermediate, and eleven highly advanced learners were selected from an initial sample of ninety-five. To make sure that the three groups were perfectly distinct from one another, gaps of 10 scores were considered among the groups. So, the elementary group consisted of those who scored between 25 and 30, the intermediate group scored 40-45 and the advanced group 55-60. Fifteen American native English speakers also participated in the study as the control 
group.

\subsection{Instruments and procedure}

Two tests were used for the study. To tap the participants' intuitions about grammaticality/ungrammaticality of the forms associated with the English article system, a grammaticality judgment (GJ) test was developed. Also, to see what potential effects their L1 may exert on article choice, the participants were tested on a translation test. The GJ test consisted of 120 items including a total of 64 test items that measured the points of interest for the study and 56 fillers. Each test item consisted of two sentences the first of which provided the necessary context for the interpretation of the second one. The participants were asked to judge the grammaticality of the second sentence and, in case it was ungrammatical, supply the correct form. There were two categories on the test which measured the use of definite and indefinite articles for DPs, equally distributed for number and specificity. In other words, article choice was tested for plural as well as singular and specific as well as non-specific nouns. For each category, both grammatical and ungrammatical items were included.

The translation test consisted of 50 sentences which included in/definite, non/specific noun phrases. The NPs were also distributed for number and position. In other words, there were equal NPs in singular and plural forms as well as in subject and object positions. Data collection took two weeks. After running the OPT, the participants took the GJ test and the translation test in the following week. The coded data was submitted to the Statistical Packages in Social Sciences software (SPSS, 16) for the purpose of analysis. For each category on the test, the mean percentage for each individual participant and later for each proficiency group was calculated. Since there were four groups of participants and one independent variable, a one-way between groups ANOVA was performed as the proper statistical procedure to see if inter-group differences existed with regard to those features in question (definiteness and specificity). For detecting possible intra-group differences, paired-samples t-tests were used.

\section{Results}

\subsection{Performance on [ \pm definite]}

This study was primarily interested in finding out the degree of difficulty learners had in using the two English articles. To that end, the mean percentage of the participants' performance on the definite/indefinite items on the GJ test is displayed in the following figure.

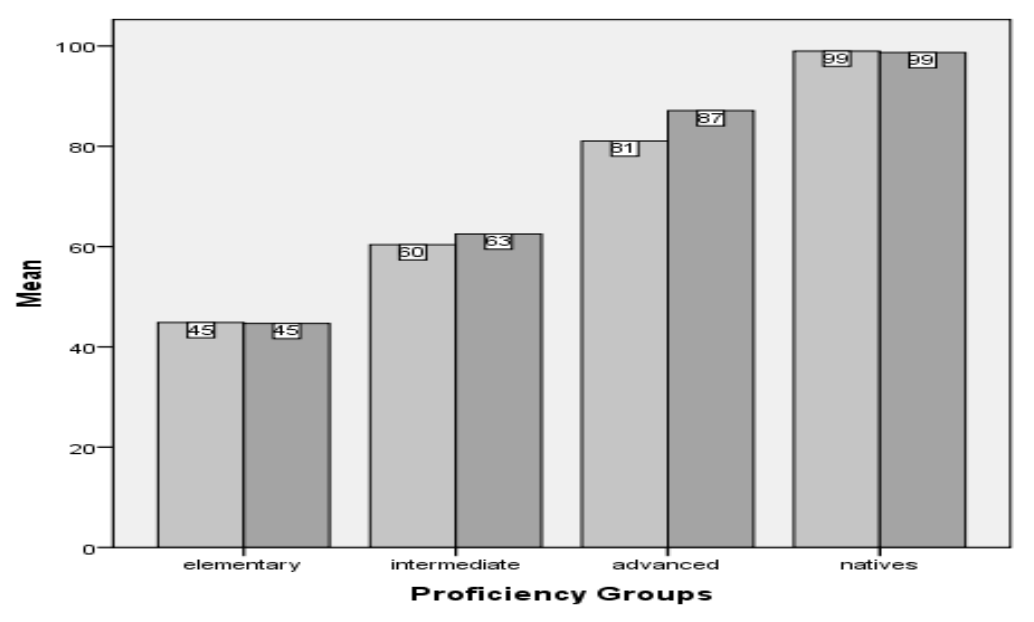

$\square$ definite
indefinite

Figure 1. Mean accuracy scores (\%) on the GJ test

It can be discerned from the above table that none of the proficiency groups could perform as well as the native control group. The one-way between groups ANOVA showed that the groups' performance on this test 
Momenzade, M., Youhanaee, M., \& Kassaian, Z.

was significantly different from each other as is presented in Table 2 below.

Table 2

ANOVA Results for Definiteness on the GJ Test

\begin{tabular}{lllllll}
\hline & Sum of Squares & df & Mean Square & F & Sig. \\
\hline definite & Between Groups & 24794.253 & 3 & 8264.751 & 160.495 & .000 \\
& Within Groups & 2677.768 & 52 & 51.496 & & \\
& Total & 27472.021 & 55 & & & \\
indefinite & Between Groups & 26276.907 & 3 & 8758.969 & 75.542 & .000 \\
& Within Groups & 6029.330 & 52 & 115.949 & & \\
& Total & 32306.238 & 55 & & & \\
\hline
\end{tabular}

The Scheffe post-hoc test also revealed that, considering the definite items, the elementary group's performance was statistically different form that of the intermediate group. The intermediate group, in turn, could not do as well as the advanced group and this failure was shown to be significant. The advanced group could not conform to the natives on definite items in the test as well. With respect to the indefinite noun phrases, the same situation existed for the lower proficiency groups. The difference in performance between the elementary and the intermediate groups was significant. Advanced learners, outperforming the intermediate and the elementary groups, were native-like in their use of the indefinite article, though. Within group differences can also be observed in Figure 1. Paired samples t-tests showed that only the advanced group's performance on in/definite items reached statistical significance. (Table 3)

Table 3

Paired Samples Test for the Advanced Group

\begin{tabular}{|c|c|c|c|c|c|c|c|c|c|}
\hline & & \multicolumn{5}{|c|}{ Paired Differences } & \multirow[t]{2}{*}{$\mathbf{t}$} & \multirow[t]{2}{*}{ dff } & \multirow[t]{2}{*}{ Sig. (2-tailed) } \\
\hline & & Mean & SD & SEM & \multicolumn{2}{|c|}{$\begin{array}{l}95 \% \text { Confidence } \\
\text { Interval of the difference }\end{array}$} & & & \\
\hline & & & & & Lower & Upper & & & \\
\hline Pair 1 & $\begin{array}{l}\text { definite- } \\
\text { indefinite }\end{array}$ & -6.061 & 6.596 & 1.989 & -10.492 & -1.629 & -3.047 & 10 & .012 \\
\hline
\end{tabular}

On the translation test, the participants were better in performance in indefinite contexts. At the advanced level, however, their performance in definite contexts was as good as that in indefinite ones (Figure 2). This superiority in performance on the translation test can be attributed to the fact that the participants were more successful in recognition and production of the grammatical forms. When ungrammatical forms were concerned, however, their knowledge was lacking.
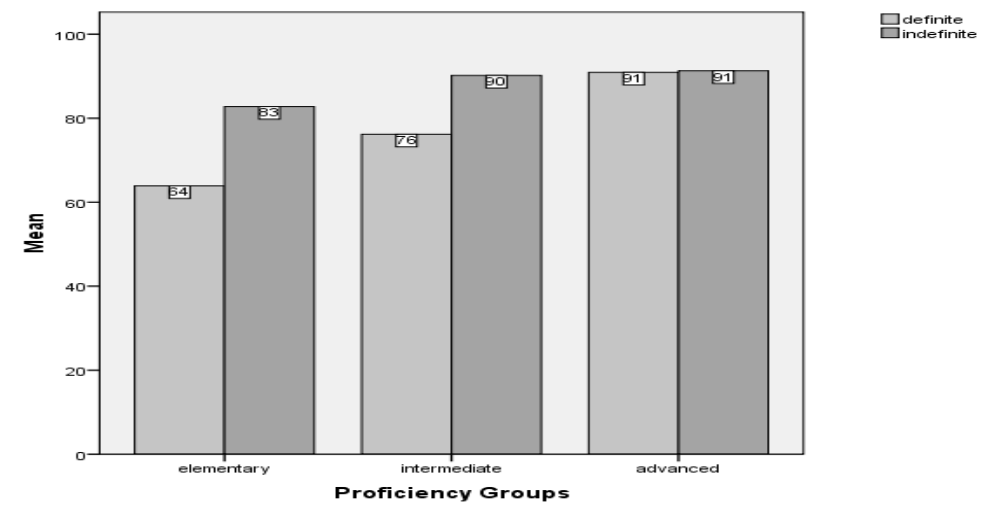

Figure 2. Mean Accuracy Scores (\%) on the Translation Test

Article suppliance by the participants on the translation test also revealed that they had more serious difficulty with using "the" for NPs in subject position. Figure 3 below displays the results: 


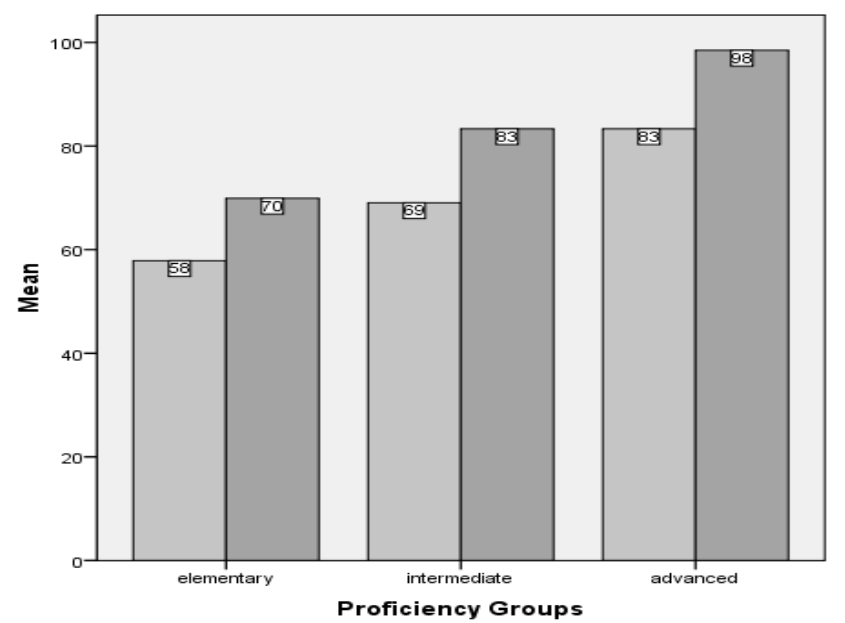

吕subject

Figure 3. Mean accuracy scores (\%) for definite NPs on the translation test

It was easier for the participants at all three levels to use the definite article for NPs in object position which is due to the fact that there is an object marker in Persian which also marks nouns for specificity (Karimi, 1990). Apparently, this object marker gave the learners the clue about article use.

\subsection{Performance on [ \pm specific]}

To find the answer to the second and third research questions, two contexts should be considered. Ionin (2003) speculates that learners will fluctuate in [+definite, -specific] and [-definite, +specific] contexts. Our participants had the following mean accuracy of scores in the above mentioned contexts:

Table 4

Performance in \pm Specific Contexts on the GJ Test

\begin{tabular}{lllll}
\hline & + definite, +specific & +definite, -specific & -definite, -specific & -definite, +specific \\
\hline elementary & $51 \%$ & $37 \%$ & $45 \%$ & $44 \%$ \\
intermediate & $73 \%$ & $44 \%$ & $67 \%$ & $58 \%$ \\
advanced & $91 \%$ & $73 \%$ & $92 \%$ & $82 \%$ \\
native control & $99 \%$ & $98 \%$ & $99 \%$ & $99 \%$ \\
\hline
\end{tabular}

As one might have expected, the degree of correct article use in the two contexts is correlated with the level of grammatical knowledge. Performance in the definite non-specific context was not as good as that in its specific counterpart for all proficiency groups showing that our participants had more doubts about using "the" for non-specific definite nouns and were clearly non-native-like even at the advanced level. Considering the indefinite context, using " $a$ " in indefinite contexts was unaffected by specificity for the elementary group as no difference could be detected. For the other two groups, however, differences could be seen in their article suppliance for the specific/non-specific indefinite nouns. Although the advanced participants were native-like in their indefinite article use in non-specific contexts, their performance was deviant from that of the native control group in specific indefinite contexts. This, however, should not be hurriedly interpreted as fluctuation because a more accurate picture can be presented when one considers the type of errors committed. This is provided in the following tables:

Table 5

Article Misuse for Singular [+definite, -specific] Nouns on the GJ Test

\begin{tabular}{llllll}
\hline \multicolumn{5}{c}{ (target: the) } \\
& No of answers & No of errors & the & a & $\varnothing$ \\
\hline elementary & 108 & 72 & $36(33 \%)$ & $39(36 \%)$ & $33(31 \%)$ \\
intermediate & 84 & 44 & $40(48 \%)$ & $21(25 \%)$ & $23(27 \%)$ \\
advanced & 66 & 10 & $56(85 \%)$ & $2(3 \%)$ & $8(12 \%)$ \\
\hline
\end{tabular}


Momenzade, M., Youhanaee, M., \& Kassaian, Z.

Table 6

Article Misuse in [-definite, +specific] Context on the GJ Test

\begin{tabular}{llllll}
\hline \multicolumn{5}{c}{ (target: a) } & \\
& No of answers & No of errors & a & the & $\varnothing$ \\
\hline elementary & 144 & 114 & $30(21 \%)$ & $46(32 \%)$ & $68(47 \%)$ \\
intermediate & 112 & 69 & $43(38 \%)$ & $24(21 \%)$ & $45(41 \%)$ \\
advanced & 88 & 22 & $66(75 \%)$ & $8(9 \%)$ & $14(16 \%)$ \\
\hline
\end{tabular}

It can be discerned from the above tables that article misuse was not the sole reason responsible for the mistakes these learners made. In both suspected contexts, article omission is as frequent as article misuse. In fact, in the [-definite, +specific] context, omitting the article is almost twice as frequent as misusing the definite article. It doesn't mean, however, that article misuse errors can be discarded as they are frequently occurring at the elementary and intermediate levels. Looking at the performance of the advanced group, it becomes apparent that the reason they do not conform to the native speakers is that they are more prone to article omission than misuse.

Results from the translation test also highlighted similar facts. As the table below shows, the elementary and intermediate groups showed different degrees of mastery over article use in \pm specific definite contexts but were insensitive to specificity in article use for indefinite nouns.

Table 7

Performance in \pm Specific Contexts on the Translation Test

\begin{tabular}{lll|ll}
\hline & + definite, +specific & +definite, -specific & -definite, -specific & -definite, +specific \\
\hline elementary & $67 \%$ & $57 \%$ & $91 \%$ & $89 \%$ \\
intermediate & $80 \%$ & $73 \%$ & $97 \%$ & $94 \%$ \\
advanced & $92 \%$ & $89 \%$ & $98 \%$ & $95 \%$ \\
\hline
\end{tabular}

The difference in performance in definite contexts, however, was due to article omission and not fluctuation as Table 7 presents:

\section{Table 8}

Article Misuse for Singular [+definite, -specific] Nouns on the Translation Test

\begin{tabular}{llllll}
\hline \multicolumn{5}{c}{ (target: the) } \\
& No of answers & No of errors & the & a & $\varnothing$ \\
\hline elementary & 108 & 40 & $36(33 \%)$ & $39(36 \%)$ & $33(31 \%)$ \\
intermediate & 84 & 7 & $40(48 \%)$ & $21(25 \%)$ & $23(27 \%)$ \\
advanced & 66 & 5 & $56(85 \%)$ & $2(3 \%)$ & $8(12 \%)$ \\
\hline
\end{tabular}

Analysis of the three groups' performance showed that the elementary group was still indeterminate about article use since they did not prefer a specific article for definite non-specific nouns. In other words, they had not learned the English article system yet. The other two groups, while improving in their article choice, had more errors of omission than misuse which is more clearly observable for the advanced group.

\section{Discussion}

Ionin et al. (2008) consider L1 transfer as one of the factors that have a crucial effect on the acquisition of articles. Based on this view, one would expect that learners with article-based L1s who are learning another article-based language like English would be accurate in their article production even at the low levels of proficiency. Though many researchers have found evidence for a positive transfer effect (Hawkins et al., 2006; Guella, Déprez, \& Sleeman, 2008; Jaensch \& Sarko, 2009), data from our Persian-speaking learners does not support it. Following the same line of discussion, one would expect such learners to transfer the properties of Persian to the L2 because they are familiar with the feature in question and are already using articles in their L1. 
The English definite article is seriously problematic for them and, in case of the indefinite article, although our advanced participants show to have mastered the English indefinite article, the expectation that learners would be accurate at lower levels of proficiency is not met. As a response to our first research question, then, Persian learners in our study do have more difficulty with the definite article but only at the advanced level. At lower levels of proficiency, both English articles pose the same degree of serious difficulty to them. The first hypothesis is, therefore, confirmed.

Though it might be unexpected to observe that Persian-speaking learners are unable to transfer their knowledge of the article system to English, a few points should be considered. First, it should be admitted that although definiteness as a feature exists in Persian and is realized on a definite suffix in the informal language, it is not overtly realized in the written formal language and, therefore, Persian-speaking learners never get instruction on that. Besides, there is no mention of that definite marker in any of Persian grammar books and only recently has it been brought into attention by Ghomeshi (2003). It is, then, evident that Persian speakers are not consciously aware that their mother tongue has a marker of definiteness and so, the notion of definiteness is not tangible for them.

As to the second research question, the participants showed a different degree of mastery in their article choice for [+definite, -specific] nouns compared with the corresponding context of [+definite, + specific] on both tests. This is not in contrast with the FH since these participants frequently omitted the article in obligatory contexts. It shows, however, that just the presence of a feature in the first language of learners does not guarantee that they would easily transfer its properties to the L2 situation. In other words, not until a feature is morphologically realized in the first language of learners, it cannot be expected to have a facilitative role in their learning of a second language. The studies that have supported positive transfer of L1 article properties to the L2 situation (Hawkins et al., 2006; Guella, Déprez, \& Sleeman, 2008; Ionin et al., 2008; Jaensch \& Sarko, 2009) have all considered languages that have overt articles (Greek, Dutch, Spanish, Arabic). It seems, however, that in case of a language that does not have an overt definite article (Persian) no positive transfer can be assumed. Also, it was shown (Figure 3 ) that NP position made a difference in article choice for definite nouns.

The participants were more successful in supplying the correct article for definite nouns in object position. The reason might be that there is an object marker (ra) in Persian. While subject NPs are usually bare in form, object NPs are mostly accompanied with "ra". Although there is controversy about the role of this marker, Karimi (1990) adequately discusses that "ra" marks specificity and not definiteness. Notwithstanding the role it plays, it seems that "ra" has provided the learners with a clue to use the with object nouns more frequently. The answer to the second research question is, then, negative, supporting the predictions of the FH. It has to be noticed that the FH does not have any predictions for article omission because it just pertains to the use of "the" and "a" and not zero as English articles. It is admitted in many books of grammar (Hewings, 1999, for instance) that English has three articles. Therefore, the fact that these participants did not show fluctuation does not mean that they were accurate in their article choice but that they overused the "zero" article in in/definite contexts.

The data also provided a no to the third research question. Apparently, the participants were unable to transfer their knowledge of indefiniteness to the L2 context at the initial state since only those at the advanced level were native-like in using the indefinite article. But why would these learners who come from a language which has an overt indefinite article fail in using its English counterpart? The first explanation one can think of is negative language transfer, regarding the fact that the indefinite article can be omitted in certain contexts in Persian (example 13 above). Second, Ionin, Ko, and Wexler (2008) assume that L2-English learners omit articles more in singular [-definite] than in singular [+definite] environments because the [+definite] article is more informative than the [-definite] article. They justify their claim on the ground that the carries a presupposition of uniqueness. It would, then, be reasonable to expect that 'if L2-learners omit articles under performance pressure, they do so when the article conveys the least amount of information, and hence omit a more than the: while a carries only the information that the DP is singular, the carries the information that the DP has a unique referent in the discourse' (p. 235). Finally, Sharma concludes that 'clarity of discourse reference and economy are major 
Momenzade, M., Youhanaee, M., \& Kassaian, Z.

considerations for [L2 speakers'] decision to use or omit an article' (2005, p. 557).

\section{Conclusion}

Analysis of data from adult Persian-speaking learners of English at three levels of proficiency showed that these learners had persistent problems with both articles and even at highly advanced levels, they could not catch up with native speakers in the use of the definite article but were able to use the indefinite article in a native-like fashion at the advanced level. Although there was no fluctuation in their article choice, these learners were not accurate either since they were found to be prone to article omission at all levels, a fact which is not predicted by the FH. Also, the participants at all three levels of grammatical knowledge were sensitive to NP position as the ratio of correct article choice for object NPs was significantly different from that for subject NPs. Generally, L1 transfer effects were traceable in article choice by Persian learners.

The present study may have several implications for teaching the English article system to Persian learners. Unlike the popular view, it is not just the definite article that is problematic. Learners should also receive detailed instruction and practice in the use of the indefinite article especially in contexts in which the article is usually omitted in Persian. As to the NP function, learners need explicit instruction on how to use articles for subject/object NPs. Therefore, the focus should be on providing efficient explanation and examples to highlight the differences between the two. Finally, considering the fact that Persian lacks an overt definite article, it is necessary to consider two types of factors and measure the significance of each one while teaching: factors that might determine how the definite article is used in English and the ones that might interfere from Persian. The question of which task type best serves instruction of this grammatical point, however, remains an open question, calling for further research.

\section{References}

Ansarin, A. (2003). Non-generic use of the definite article by Persian learners. Journal of Faculty of Letters and Humanities, 47(190), 1-11.

Anzali, H. (1985). Dastur-e zaban-e Farsi [Persian grammar]. Urumiyeh: Anzali.

Atay, Z. (2010). Second language acquisition of the English article system by Turkish learners: The role of semantic notions. Unpublished masteral thesis, Middle East Technical University, Ankara, Turkey.

Avery, P., \& Radišić, M. (2007). Accounting for variability in the acquisition of English articles. In Proceedings of the 2nd Conference on Generative Approaches to Language Acquisition North America (GALANA) (pp. 1-11). Somerville, MA: Cascadilla Proceedings Project.

Dabaghi, A., \& Tavakoli, M. (2009). A comparison of the effects of corrections on definite/indefinite articles and regular/irregular past tense forms: A case of Iranian EFL learners. Asian EFL Journal, 11(4), 90-114.

Ghomeshi, J. (2003). Plural marking, indefiniteness, and the noun phrase. Studia Linguistica, 57(2), 47-74.

Guella, H., Déprez, V., \& Sleeman, P. (2008). Article choice parameters in L2. In Proceedings of the 9th Generative Approaches to Second Language Acquisition Conference (GASLA). Somerville, MA: Cascadilla Proceedings Project.

Hawkins, R. et al. (2006). Accounting for English article interpretation by L2 speakers. In S. Foster-Cohen, M. Medved Krajnovic, \& J. Miihaljevic Djigunovic (Eds.), EUROSLA Yearbook. Amsterdam: John Benjamins.

Hewings, M. (1999). Advanced grammar in use. Cambridge: Cambridge University Press.

Ionin, T. (2003). Article semantics in second language acquisition. Unpublished doctoral dissertation, MIT.

Ionin, T., Ko, H., \& Wexler, K. (2003). Specificity as a grammatical notion: Evidence from L2-English article use. In G. Garding \& M. Tsujimura (Eds.), WCCFL 22 proceedings (pp. 245-258). Somerville, MA: Cascadilla Press.

Ionin, T., Ko, H., \& Wexler, K. (2004). Article semantics in L2-acquisition: The role of specificity. Language Acquisition, 12(1), 3-69. http://dx.doi.org/10.1207/s15327817la1201_2

Ionin, T., Zubizarreta, M. L., \& Maldonado, S. B. (2008).Sources of linguistic knowledge in the second language 
Article choice by Persian EFL learners: Evidence against the Fluctuation Hypothesis?

acquisition of English articles. Lingua, 118, 554-576. http://dx.doi.org/10.1016/j.lingua.2006.11.012

Ionin, T., Ko, H., \& Wexler, K. (2008). The role of semantic features in the acquisition of English articles by Russian and Korean speakers. In J. M. Liceras et al. (Eds.), The role offormal features in second language acquisition (pp. 226-269). Lawrence Erlbaum Associates.

Ionin, T., Zubizarreta, M. L., \& Philippov, V. (2009). Acquisition of article semantics by child and adult L2-English learners. Bilingualism: Language and Cognition, 12(3), 337-361. http://dx.doi.org/10.1017/S1366728909990149

Jaensch, C., \& Sarko, G. (2009). Sources of fluctuation in article choice in English and German by Syrian Arabic and Japanese native speakers. EUROSLA Yearbook, 9, 33-55. http://dx.doi.org/10.1075/eurosla.9.04jae

Karimi, S. (1990). Obliqueness, specificity, and discourse functions: Ra in Persian. Linguistic Analysis, 3, 139-191.

Kim, K., \& Lakshmanan, U. (2008). L2 article semantics and second language processing. In Proceedings of the 9th Generative Approaches to Second Language Acquisition Conference (GASLA) (pp. 103-117). Somerville, MA: Cascadilla Proceedings Project.

Ko, H, Ionin, T., \& Wexler, K. (2006). Adult L2-learners lack the Maximality presupposition, too! In Proceedings of the Inaugural Conference on Generative Approaches to Language Acquisition-North America, Honolulu, HI, (vol. 4, pp. 171-182). Storrs, CT: University of Connecticut Occasional Papers in Linguistics.

Ko, H., Perovic, A., Ionin, T., \& Wexler, K. (2008). Semantic universals and variation in L2 article choice. Proceedings of the 9th Generative Approaches to Second Language Acquisition Conference (GASLA 2007), Iowa, US, 18-20 May 2008, (pp. 118-129). Somerville, MA: Cascadilla Proceedings Project.

Ko, H., Ionin, T., \& Wexler, K. (2009). L2 acquisition of English articles by Korean speakers. In CH. Lee, G. B. Simpson, \& Y. Kim (Eds.), The handbook of East Asian Psycholinguistic (pp. 286-304). Cambridge: Cambridge University Press.

Lyons, C. H. (1999). Definiteness. Cambridge: Cambridge University Press. http://dx.doi.org/10.1017/CBO9780511605789

Master, P. (1983). Teaching the art of the article. Paper presented at the 17th Annual TESOL Convention, Toronto, Canada.

Master, P. (1987). A cross-linguistic interlanguage analysis of the acquisition of the English article system. Unpublished doctoral dissertation, UCLA.

Mayo, M. (2009). Article choice in L2 English by Spanish speakers. In M. Mayo \& R. Hawkins (Eds.) Second language acquisition of articles: Empirical findings and theoretical implications (pp. 13- 37). John Benjamines Publishing Company.

McEldowney, P. L. (1977). A teaching grammar of the English article system. International Review of Applied Linguistics, 15(2), 95-112.

Mobini, F. (2006). Farsi speaking learners' differential commands of semantic vs. pragmatic definite types: a cross linguistic study. Unpublished doctoral dissertation, University of Isfahan.

Rahmani, F. (2010). A case of teaching English in/definite articles to Iranian low-intermediate EFL learners: implementation of tasks into explicit and implicit grammar instruction. Unpublished masteral thesis, University of Isfahan, Iran.

Sharma, D. (2005). Language transfer and discourse universals in Indian English article use. Studies in Second Language Acquisition, 27, 535-566. http://dx.doi.org/10.1017/S0272263105050242

Snape, N., Leung, Y-K. I., \& Ting, H-C. (2006). Comparing Chinese, Japanese, and Spanish speakers in L2 English article acquisition: evidence against the Fluctuation Hypothesis? In Proceedings of the 8th Generative Approaches to Second Language Acquisition Conference (GASLA), Banff, Canada, 27- 30 April (pp. 132- 139). Somerville, MA: Cascadilla Proceedings Project.

Snape, N. (2009). Exploring Mandarin Chinese speakers' L2 article use. In N. Snape, Y-K. I. Leung, \& M. Sharwood Smith (Eds.), Representational deficits in SLA, Studies in honor of Roger Hawkins (pp. 27-53). John Benjamins Publishing Company.

Yang, M., \& Ionin, T. (2009). L2 English articles and the computation of uniqueness. In Proceedings of the 3rd 
Momenzade, M., Youhanaee, M., \& Kassaian, Z.

Conference on Generative Approaches to Language Acquisition North America (GALANA),

Connecticut, US, 4- 6 September 2008 (pp. 325-335). Somerville, MA: Cascadilla Proceedings Project.

Zdorenko, T., \& Paradis, J. (2008). The acquisition of articles in child second language English: Fluctuation, transfer or both? Second Language Research, 24, 227-250.

http://dx.doi.org/10.1177/0267658307086302 